\title{
ANÁLISE DO POSICIONAMENTO DE INDÚSTRIAS CALÇADISTAS NA REGIÃO DE FRANCA
}

\section{RESUMO}

Este estudo analisa estratégias de posicionamento da indústria calçadista da região de Franca (SP) com relação ao mercado interno. O trabalho apresenta um panorama da indústria calçadista nacional; em seguida, são apresentados os resultados de uma pesquisa empírica empreendida com empresas da região. Uma análise de conglomerados permitiu identificar quatro diferentes grupos de empresas com base em cinco variáveis (preços praticados, custos de produção, qualidade dos produtos, tecnologia de produção e capacidade de inovação), utilizando três diferentes estratégias: foco no segmento de calçados masculinos para um público de renda baixa (grupo 1), baixo custo (grupos 2 e 3), e diferenciação por meio de produtos de melhor qualidade e preços mais altos (grupo 4). Ao final, foram sugeridas alternativas estratégicas para as empresas consideradas em posição desfavorável em comparação às concorrentes.

\author{
Alfredo José Machado Neto \\ Uni-FACEF \\ Janaina de Moura Engracia Giraldi \\ FEARP-USP
}

\begin{abstract}
This study analyzes the footwear industry in Franca region (SP), with regard to positioning strategies in the domestic market. An overview of the national footwear industry is followed by results of an empirical research performed with shoe manufacturers from the region of Franca. A cluster analysis resulted in a four group classification based on five variables (prices, production costs, product quality, production technology and innovation capacity). Groups are characterized by the use of one of the following strategies: focus on the male shoe low income segment (group 1); low costs (groups 2 and 3); and differentiation by means of high quality products at higher prices (group 4). In closing, strategic alternatives were suggested to firms considered in an unfavorable position compared to their competitors.
\end{abstract}

PALAVRAS-CHAVE Posicionamento, indústria calçadista, estratégia, vantagem competitiva, grupos estratégicos. KEYWORDS Positioning, footwear industry, strategy, competitive advantage, strategic clusters. 


\section{INTRODUÇÃO}

Dentre os atuais desafios enfrentados por empresas em busca de competitividade, destaca-se o gerenciamento de tecnologias de informação, que torna indistinguíveis as tradicionais linhas de demarcação entre mercados e empresas, ao mesmo tempo em que acelera o ritmo das tomadas de decisão (DAY, 1990). Outro desafio refere-se à rápida globalização dos mercados e ao crescimento sem precedentes do comércio internacional nas últimas décadas (ZHANG, 1997).

Nesse cenário, a disputa por clientes torna-se acirrada, conferindo maior importância às estratégias de marketing. O planejamento estratégico corporativo aproxima-se das ferramentas de marketing, levando estratégias mercadológicas a se confundirem com ações de estratégia (ANDERSON; VINCZE, 2000).

As estratégias de marketing apóiam-se na análise das necessidades dos indivíduos e das organizações, seguindo a evolução do mercado de referência e identificando diferentes produtos, mercados e segmentos, já existentes e potenciais. Para isso, é essencial a compreensão da diversidade de necessidades e de como satisfazê-las. Segundo Lambin (2000), o marketing estratégico orienta a empresa para as oportunidades existentes ou busca oportunidades atrativas e adaptadas aos seus recursos, com potencial de lucratividade e crescimento.

No marketing estratégico, destacam-se três atividades fundamentais: a segmentação, o posicionamento e a definição de alvos, que representam o escopo competitivo de uma empresa (LAMBIN, 2000). O termo posicionamento de mercado é utilizado para designar as decisões tomadas por uma empresa para determinar o espaço que sua marca e imagem corporativa ocupam, incluindo os benefícios a serem oferecidos e os segmentos almejados (RIES; TROUT, 1999).

Nesse contexto, a proposta do presente artigo é apresentar uma análise das indústrias calçadistas da região de Franca relativa às suas estratégias de posicionamento no mercado interno, caracterizando os grupos que utilizam estratégias semelhantes de atuação no mercado (CRAVENS, 1994). Segundo Hooley, Saunders e Piercy (2001), a identificação de grupos estratégicos pode ser útil para que as empresas compreendam sua vulnerabilidade a um ataque competitivo, devendo monitorar e responder às estratégias dos concorrentes em seu grupo, tais como ataques de promoção, mudanças na embalagem e investimentos em propaganda.

Inicialmente, o trabalho descreve o panorama da indústria calçadista nacional, destacando a importância do setor para a economia brasileira devido ao seu desempenho no mercado externo e à sua capacidade de geração de empregos. Em seguida, são apresentados os resultados de uma pesquisa empírica empreendida com as empresas calçadistas da região, de modo a investigar suas estratégias de atuação no mercado interno. A técnica estatística empregada para verificar a composição dos grupos estratégicos é a análise de conglomerados (HAIR et al., 1998), com base em suas estratégias de posicionamento no mercado brasileiro.

\section{Empresas calçadistas no Brasil}

Segundo a Abicalçados (2006), o setor calçadista brasileiro é composto por mais de 8,4 mil indústrias, que produzem cerca de 725 milhões de pares por ano, sendo que 189 milhões são destinados à exportação. É um dos setores da indústria que mais gera empregos no país. No ano de 2004, cerca de 313 mil trabalhadores atuavam diretamente na indústria. Pouco menos da metade dos postos de trabalho, $45,7 \%$, estão no estado do Rio Grande do Sul, seguido pelo estado de São Paulo, com 18,2\%, e pelo estado do Ceará, com 14,7\% dos empregos do setor. Segundo Sampaio (2006), mesmo que o setor calçadista brasileiro venha incorporando tecnologias modernas de gestão e de processos, continua sendo um segmento industrial que permanece intensivo em mão-de-obra.

A cadeia produtiva do couro e do calçado é composta por uma grande variedade de fornecedores de matéria-prima, máquinas e componentes, que, aliada à tecnologia de produtos e inovações, faz do setor calçadista brasileiro um dos mais importantes do mundo. Encontram-se instaladas no Brasil mais de 1.500 indústrias de componentes, cerca de uma centena de fábricas de máquinas e equipamentos, e mais de 800 empresas especializadas no curtimento e acabamento do couro, que processam, anualmente, mais de 45 milhões de peles (Abicalçados, 2006).

O mercado interno de calçados absorve três quartos da produção nacional anual, constituindo a maior parte do mercado no setor (ACINH, 1999). No entanto, no mercado interno observa-se acentuada inclinação ao consumo de produtos mais baratos, com materiais menos nobres e de menor valor agregado, devido ao baixo poder aquisitivo da população.

O consumo de calçados no Brasil aumentou significativamente nos primeiros anos do plano antiinflacionário, o Plano Real, no período de 1994 a 1996, em decorrência ao maior poder aquisitivo da população resultante da redistribuição de renda provocada pela queda abrupta da inflação. No entanto, a progressiva redução das barreiras à importação e a sobrevalorização do real provocaram 
aumento das importações de calçados. O aumento das taxas de juros e outras medidas para manter o Plano Real, adicionados aos fatores previamente apontados, levaram a economia à estagnação e o setor calçadista a uma grande crise (PROCHNIK; UNE, 2002). O ciclo de valorização do real, iniciado em 2005, tem dificultado a penetração dos calçados brasileiros no mercado internacional e facilitado a importação de produtos de menor valor agregado, em especial os chineses (MACHADO NETO, 2006).

\section{Pólos calçadistas no Brasil}

Um estudo do Sindicato da Indústria de Calçados de Franca (2002) mostra que, historicamente, a produção de calçados no Brasil concentra-se em dois pólos principais. O primeiro deles, situado no vale dos Sinos (RS), especializado em calçados femininos, responde por $40 \%$ da produção nacional de calçados e por $75 \%$ das exportações totais; e gera quase 50\% dos empregos do setor. O segundo, localizado na cidade de Franca (SP), com cerca de 760 empresas, preponderantemente dedicadas à fabricação de calçados de couro masculino, produz cerca de 36 milhões de pares por ano, representando $6 \%$ da produção nacional e 3\% das exportações totais do Brasil.

As empresas do vale dos Sinos possuem vantagens em relação a outros pólos produtores, pois a região concentra fornecedores de matérias-primas, acessórios, componentes e equipamentos necessários à produção (PICCININI, 1990). O fato de produzirem preferencialmente para o mercado externo forçou as empresas calçadistas do vale dos Sinos a buscarem atualização tecnológica para cumprirem as normas estabelecidas por exportadores, motivando também a instalação de fornecedores para a indústria na região.

No estado de São Paulo, além de Franca, destacam-se ainda a cidade de Birigüi, conhecida como a capital nacional do calçado infantil, e a cidade de Jaú, importante pólo produtor de calçados femininos. As empresas localizadas nessas três cidades do estado de São Paulo - Franca, Birigüi e Jaú - absorvem cerca de 18\% da mão-de-obra empregada pelo setor (SINDIFRANCA, 2002).

Segundo Piccinini (1990) e Machado Neto (2004), a maior parte das grandes e médias empresas de Franca produz tanto para o mercado externo como para o interno. Segundo o autor, essas empresas conseguem manter sua produção relativamente constante, pois, quando o mercado interno está em recessão, a exportação garante um nível mínimo de demanda.

Destacam-se, ainda, outros dois pólos tradicionais da indústria calçadista, os de Santa Catarina e de Minas Gerais. A indústria de calçados de Santa Catarina, espe- cializada em calçados femininos, fabrica cerca de 1\% da produção nacional, enquanto o setor calçadista de Minas Gerais é composto por cerca de 2.200 empresas, concentradas em Belo Horizonte e em Nova Serrana, responsáveis por cerca de 10\% da produção nacional (SINDIFRANCA, 2002).

A partir da década de 1990, com a migração de grandes empresas das regiões Sul e Sudeste, surgiu um novo pólo calçadista no Nordeste, decorrente de dois fatores principais: amplos subsídios concedidos pelos governos de estados nordestinos; e o fato de os salários dos trabalhadores desses estados corresponder, em média, à metade dos praticados na cidade de Franca e do vale dos Sinos (HENRIQUES, 1999). O estudo do Sindicato da Indústria de Calçados de Franca (SINDIFRANCA, 2002) destaca que as exportações nordestinas, no ano de 2000, corresponderam a cerca de $14 \%$ do total de calçados exportados pelo Brasil.

\section{Estratégias competitivas e posicionamento}

Aa competitividade empresarial pode ser compreendida como a busca de valor para o cliente por meio de estratégias para obter e manter a liderança de mercado. As estratégias gerais podem ser de três tipos: diferenciação, liderança em custos e estratégia de foco. Um negócio é diferenciado quando desempenha certas atividades adicionadoras de valor, de forma a levar à superioridade em dimensões valiosas para os clientes. Para que essas atividades sejam lucrativas, os clientes devem estar dispostos a pagar pelos benefícios um excedente a seus custos adicionais (DAY; WENSLEY, 1998). Uma empresa e seus produtos podem se diferenciar de diversas maneiras, como, por exemplo, fornecer serviço superior, possuir uma marca forte, oferecer características inovadoras, ou prover qualidade superior nos produtos.

A segunda estratégia competitiva genérica baseia-se em menor custo. A vantagem de custo é obtida se a empresa desempenha maioria de suas atividades com custo menor do que a concorrência, mesmo oferecendo um produto semelhante. Para Porter (1986), atingir a posição de custo baixo exige, freqüentemente, alta participação de mercado, ou outras posições vantajosas, como acesso favorável a matérias-primas, por exemplo. Essa estratégia pode exigir também produtos de fabricação simplificada; manutenção de uma vasta linha de produtos inter-relacionados para diluir custos; e atendimento completo aos principais segmentos de mercado, de modo a expandir volume.

Finalmente, a terceira estratégia competitiva genérica baseia-se em foco, e consiste em selecionar um grupo comprador, um segmento da linha de produtos ou um 
mercado geográfico (PORTER, 1986). Essa estratégia presume que a empresa atenda ao seu alvo de forma mais eficaz ou eficiente do que os concorrentes que competem de modo mais amplo no mercado. Conseqüentemente, a empresa atinge a diferenciação, melhor satisfazendo às necessidades de seu alvo particular, conseguindo custos mais baixos ao desempenhar seu foco, ou ambos.

Para Slack (1993), oferecer vantagem competitiva em manufatura significa fazer melhor. Os consumidores e os concorrentes são fundamentais para uma operação de manufatura competitiva, porque definem as metas sucintamente: satisfazer o primeiro (fazer melhor para lhe agradar), e ser melhor que o segundo (fazer melhor para manter a vantagem). Para o autor, considerar de forma conjunta o que é importante para o consumidor e a medida de desempenho dos concorrentes leva ao estabelecimento de prioridades e ao aperfeiçoamento da operação, gerando vantagens. Qualquer operação de manufatura deveria ser capaz de estabelecer a importância relativa de seus objetivos de desempenho. Ser melhor em cada objetivo contribui para a competitividade como um todo. Assim, compreender quais devem ser as metas de desempenho da manufatura pode ser um começo para o alcance de vantagem (SLACK, 1993).

Uma vez definida a estratégia genérica de atuação de mercado e os fatores de competitividade, é necessário que a empresa determine sua estratégia de posicionamento. O posicionamento pode ser definido como a projeção de uma imagem da oferta de produtos e serviços da empresa, de forma que os clientes compreendam e apreciem o que eles representam (KOHLI; LEUTHESSER, 1993). A definição de Ries e Trout (1999) para posicionamento considera como a empresa posiciona o produto na mente dos consumidores. Kapferer (1998, p. 88) compartilha da mesma posição, ao afirmar que "por posicionamento queremos evidenciar as características distintivas em relação à concorrência e motivadoras para o público".

Para Dimingo (1988), posicionamento é o processo de distinguir a empresa ou produto dos seus concorrentes com base em dimensões reais - produtos ou valores significativos para seus consumidores - para tornar-se preferido no mercado. Dessa forma, o posicionamento é como a empresa ou a marca se insere no ambiente competitivo, de forma a ocupar um espaço único no mercado e na mente do consumidor. Um aspecto peculiar é a diferença que esse autor faz entre posicionamento de mercado e posicionamento psicológico.

O posicionamento de mercado relaciona-se diretamente às questões do marketing estratégico, especificamente à escolha de uma estratégia de segmentação, englobando as etapas de segmentação, avaliação e seleção de segmentosalvo. Já o termo posicionamento psicológico reflete a intenção da empresa quanto à mensagem e às associações pretendidas na mente do consumidor, e quanto aos caminhos para atingir esse objetivo, partindo da definição prévia dos segmentos que serão alvos das ações. Assim, promove-se a identificação das vantagens competitivas presentes na operação; a seleção de vantagens com maior aderência e apelo em relação aos segmentos-alvo; e a seleção de apelos de comunicação. A posição de um produto é um complexo de percepções, impressões e sentimentos do consumidor sobre o produto em relação à concorrência. Os profissionais de marketing devem planejar o posicionamento de produtos visando a maior vantagem possível nos mercados-alvo selecionados, e devem elaborar compostos de marketing que criem as posições pretendidas (KOTLER; ARMSTRONG, 1998). Nesse contexto, destaca-se o conceito de grupos estratégicos, conjuntos de empresas que utilizam estratégias semelhantes de posicionamento de mercado, e se caracterizam por dimensõeschave (CRAVENS, 1994). Para Cravens, tais dimensões variam consideravelmente de indústria a indústria, e incluem, ao menos, o escopo do negócio e o comprometimento de seus recursos. Dessa forma, pode haver ampla diversidade na definição de grupos estratégicos de uma indústria a outra.

\section{ESTUDO}

A pesquisa de campo caracteriza-se como uma pesquisa descritiva com o objetivo de apresentar características da indústria calçadista da região de Franca (SP); é um levantamento de campo com grande amplitude e do tipo transversal.

\section{Caracterização e representatividade da amostra}

De acordo com Machado Neto (2004), existem 760 indústrias de calçados na cidade de Franca: 552 microempresas; 130 empresas de pequeno porte; 65 empresas de porte médio; e 13 empresas de grande porte. As microempresas foram excluídas desse universo, pois a pesquisa tinha por foco analisar o comportamento de exportação, e a atuação das microempresas não é significativa quando se trata de comércio internacional. A metodologia utilizada para o enquadramento das empresas por porte é a adotada pelo IBGE e pelo Sebrae (2004), e considera apenas o número de empregados diretos, o que é comum em trabalhos sobre o tema, tais como os de Carvalho Neto (2004), Dourado (2001), Smith (2000) e Figueiredo e Almeida (1988). 
Para determinar o tamanho da amostra utilizada no estudo, partiu-se das seguintes premissas: (1) população finita; (2) erro admitido de 5\%, com nível de confiança desejado de 95\%; (3) máxima indeterminação, ou seja, probabilidades associadas iguais a 0,5 . Com base nessas hipóteses, a amostra deveria ser composta por 137 empresas (MATTAR, 1996).

Como não havia estimativa do percentual de retorno de questionários enviados à indústria calçadista e devido ao universo relativamente pequeno a ser pesquisado, optou-se por enviar o questionário, por e-mail, a todas as 208 empresas (pequenas, médias e grandes) constantes do Cadastro da Indústria Calçadista de Franca. Dessas empresas, 146 colaboraram com a pesquisa, retornando os questionários respondidos, o que representa uma significativa taxa de retorno, de mais de $70 \%$. Dessa forma, uma grande parcela do universo desejado foi analisada, e considerada suficiente para as análises estatísticas empreendidas na pesquisa, com a limitação, no entanto, de que amostras obtidas via correio eletrônico são passíveis de viés de auto-seleção nas respostas.

Dois questionários incompletos foram descartados. Assim, a amostra da pesquisa foi composta por $144 \mathrm{em}-$ presas, quantidade compatível à calculada anteriormente, e que permite trabalhar com erro amostral de 4,6\%, taxa inferior aos $5 \%$ que se tinha estabelecido como erro máximo admitido nesta investigação.

As perguntas feitas às empresas tratavam dos seguintes aspectos: ano de fundação, número de empregados, produção de pares ao dia, capacidade ociosa média, faturamento mensal médio, porcentagem de calçados de couro, sintéticos e de tecido, porcentagem de calçados masculinos, femininos e infantis, e segmento focado (baixa renda, clas- se média, classe alta). Com relação às variáveis utilizadas para agrupar as empresas, solicitou-se que cada empresa respondesse a perguntas sobre seu próprio posicionamento em relação à concorrência, cobrindo os seguintes aspectos: preço do produto, nível de custo, tecnologia de produção, qualidade do produto e capacidade de inovação. Para cada item, foi empregada uma escala intervalar de cinco pontos, reproduzida no Quadro 1.

\section{Análise de conglomerados}

A análise de conglomerados, também denominada análise de clusters, classifica as observações de modo que cada uma seja semelhante às demais dentro de um grupo, com base em critérios preestabelecidos. Na determinação dos grupos, o objetivo é que as observações próximas - segundo a métrica selecionada - sejam agrupadas conjuntamente, enquanto as maiores distâncias separem os grupos. De acordo com Hair et al. (1998), os grupos resultantes devem exibir alta homogeneidade interna e alta heterogeneidade externa.

Primeiramente, neste estudo, foi realizada uma análise de conglomerados do tipo hierárquico para a seleção do número de grupos de empresas. Conforme mencionado anteriormente, as variáveis escolhidas para agrupar os casos foram as respostas relativas aos seguintes aspectos: preço do produto, nível de custo, tecnologia de produção, qualidade do produto e capacidade de inovação. O método de agrupamento escolhido foi o de Ward, e a medida de distância foi a euclidiana ao quadrado.

Ao analisar os coeficientes de aglomeração, considerouse que o número de clusters adequado é igual a quatro. Em seguida, foi efetuada uma análise do tipo não-hierárquica, com as mesmas variáveis, de forma a obter uma compo-

Quadro 1 - Escala usada para mensurar o desempenho com relação aos concorrentes

\begin{tabular}{|c|c|c|c|c|c|c|}
\hline \multirow[b]{2}{*}{ Mais barato } & \multicolumn{5}{|c|}{ Preço do produto } & \multirow[b]{2}{*}{ Mais caro } \\
\hline & 1 & 2 & 3 & 4 & 5 & \\
\hline \multicolumn{7}{|c|}{ Nível de custos } \\
\hline \multirow[t]{2}{*}{ Maior custo de produção } & 1 & 2 & 3 & 4 & 5 & Menor custo de produção \\
\hline & \multicolumn{5}{|c|}{ Tecnologia de produção } & \\
\hline \multirow[t]{2}{*}{ Tecnologicamente avançado } & 1 & 2 & 3 & 4 & 5 & Tecnologicamente atrasado \\
\hline & \multicolumn{5}{|c|}{ Qualidade do produto } & \\
\hline \multirow[t]{2}{*}{ Qualidade inferior } & 1 & 2 & 3 & 4 & 5 & Qualidade superior \\
\hline & \multicolumn{5}{|c|}{ Capacidade de inovação } & \\
\hline $\begin{array}{l}\text { Maior capacidade de desenvolver } \\
\text { novos produtos }\end{array}$ & 1 & 2 & 3 & 4 & 5 & $\begin{array}{l}\text { Menor capacidade de desenvolver } \\
\text { novos produtos }\end{array}$ \\
\hline
\end{tabular}


sição otimizada dos quatro grupos identificados. Nesta nova análise, o número de casos encontrados em cada conglomerado é mostrado na Tabela 1.

\section{ANÁLISE DOS RESULTADOS}

A Tabela 1 mostra as médias das respostas que cada grupo forneceu às variáveis estratégicas. A escala utilizada possui cinco pontos: quanto mais a resposta estiver próxima do número 5, mais forte a empresa se considera em relação à concorrência (a escala de alguns itens foi revertida, quando necessário).

Observa-se, na Tabela 1, que o grupo 1 é o que se atribui tecnologias de produção menos avançadas, padrão de qualidade mais baixo, menor capacidade de desenvolver novos produtos, custos de produção reduzidos (maiores apenas que os do grupo 4), e comercializa seus produtos a preços relativamente baixos (só mais elevados do que os do grupo 2). Como não se observa uma real vantagem de custos em relação aos outros grupos, pois a qualidade dos produtos é inferior, pode-se supor que as empresas do grupo 1 seguem a estratégia genérica de direcionar sua oferta a um segmento específico de mercado que demanda produtos de qualidade e preços mais baixos. Ademais, as empresas do grupo 1 são, predominantemente, empresas pequenas e com menor capacidade de inovação.

O grupo 2 se atribui a posição de preço mais baixo dos grupos, custos baixos de produção (só maiores que os do grupo 3), tecnologia com tendência avançada, alta qualidade de produtos, e alta capacidade de inovação. Pode-se inferir que o grupo 2 busca a estratégia genérica de menor custo, uma vez que as empresas do grupo conseguem desempenhar a maioria de suas atividades com custo menor do que a concorrência enquanto oferece um produto semelhante. A liderança de custos é normalmente atingida por empresas que oferecem produtos padronizados ou baratos, com vantagem de custos obtida por ope- ração em larga escala e pela diluição dos custos indiretos e de custos diretos de fabricação, além de investimento em fábricas e equipamentos que proporcionem reduções de custos. Observa-se, também, que as empresas deste grupo possuem vantagem de custos em relação às empresas do grupo 1.

O grupo 3 declarou vender seus produtos a preços mais altos, com os custos de produção mais baixos entre os grupos, o que leva a crer que as margens de lucro deste grupo são mais altas do que as dos demais. A tecnologia, assim como a do grupo 2 , tende a ser avançada, mas a capacidade de inovação dessas empresas é limitada. A qualidade dos produtos ofertados pelo grupo 3 é considerada boa. Assim como as empresas do grupo 2, as que fazem parte do grupo 3 parecem seguir a estratégia genérica de menor custo, que se reflete em menores margens de lucro.

Finalmente, o grupo 4 considera que possui os preços mais altos, a tecnologia mais avançada, e a maior capacidade de desenvolver novos produtos. Os custos de produção das empresas deste grupo, porém, são considerados os mais elevados. Embora o volume produzido e a tecnologia utilizada proporcionem economias de escala, os custos mais elevados decorrem da produção de calçados com maior valor agregado, com a utilização de insumos de produção diferenciados e mais caros. A qualidade dos produtos, por conseguinte, é a mais alta entre os grupos. Dessa forma, observa-se que as empresas do grupo 4 buscam a estratégia genérica de diferenciação, procurando superioridade nas dimensões valiosas para os clientes; neste caso, a qualidade da matéria-prima.

O Gráfico 1 mostra as diferenças entre os grupos de indústrias calçadistas de Franca.

Para caracterizar as empresas que compõem cada grupo apresentado, foram analisados os dados referentes ao porte das empresas, número de empregados, produção em termos de quantidades de pares fabricados por dia, faturamento mensal médio e capacidade ociosa média. Em seguida, foram analisados o tipo de produto fabrica-

Tabela 1 - Número de casos e médias das variáveis estratégicas para cada grupo

\begin{tabular}{|c|c|c|c|c|c|c|}
\hline GRUPOS & NÚMEROS DE CASOS & \multicolumn{5}{|c|}{ VARIÁVEIS DE COMPARAÇÃO (MÉDIAS) } \\
\hline & & PREÇO & CUSTO & TECNOLOGIA & QUALIDADE & INOVAÇÃO \\
\hline 1 & 38 & 2,95 & 2,87 & 2,29 & 3,45 & 2,29 \\
\hline 2 & 48 & 2,60 & 3,54 & 3,79 & 4,25 & 4,63 \\
\hline 3 & 27 & 3,33 & 3,81 & 3,78 & 4,15 & 2,33 \\
\hline 4 & 31 & 3,87 & 1,81 & 4,16 & 4,48 & 4,68 \\
\hline
\end{tabular}


do a partir do material preponderante na fabricação e o público-alvo de cada um dos grupos.

Com relação ao porte das empresas que compõem cada grupo, verifica-se que o grupo 1 é constituído, predominantemente, por empresas pequenas, que representam $71 \%$ do total do grupo, o que se coaduna com as estratégias observadas neste grupo, de preço baixo; custos de produção reduzidos; qualidade inferior; pouca tecnologia; e menor capacidade de inovação. O grupo 2, por sua vez, apresenta 15 empresas de porte médio, representando cerca de $31 \%$ do total do grupo. No grupo 3, há predominância de empresas de pequeno porte, assim como no grupo 1. Entretanto, as empresas deste grupo se posicionam com custos baixos, provavelmente derivados da tecnologia mais avançada do que a utilizada pelas empresas daquele grupo (Tabela 2).

Finalmente, o grupo 4 possui a maior participação de empresas de médio e grande porte em relação ao total do grupo. Conforme descrito anteriormente, as empresas deste grupo se posicionam com a tecnologia mais avançada, a maior capacidade de inovação e a melhor qualidade, e declaram ter os preços mais altos, além dos maiores custos de produção.

Uma vez que o porte das empresas foi definido com base no número de funcionários, a pesquisa mostrou que o grupo 4 é o que possui empresas com o maior número de empregados, com média igual a 260. Em seguida, apresentam-se os grupos 1, com média de 124, e 2, cuja média é de 103, ao passo que o grupo 3 é o que possui menos empregados entre as empresas amostradas, com média igual a 83 .

Os números relativos ao porte das empresas e ao número de empregados apresentados nos grupos guardam consonância com os levantados em relação à produção das empresas da amostra, medida pela quantidade de pares fabricados por dia. A Tabela 3 permite verificar que mais de 35\% das indústrias de calçados que compõem o grupo 2 produzem mais de mil pares de calçados por dia. Tal produção elevada, aparentemente se relaciona ao posicionamento estratégico deste grupo, que combina polí-

Gráfico 1 - Desempenho dos grupos nas variáveis estratégicas

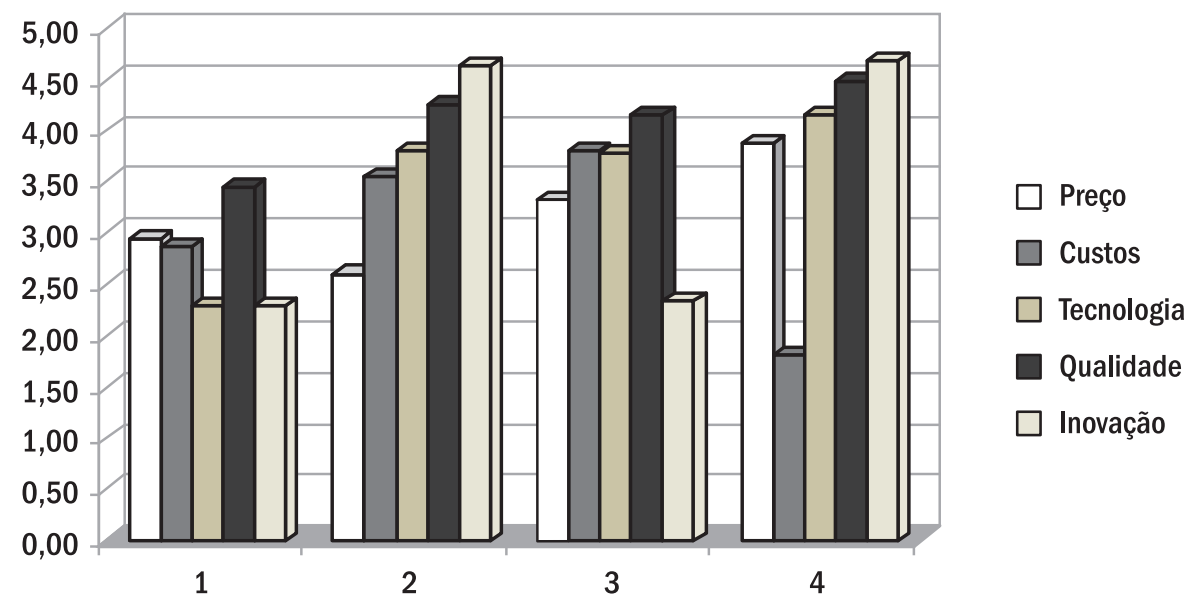

Tabela 2 - Porte das empresas em cada grupo

\begin{tabular}{|l|c|c|c|c|c|}
\hline \multicolumn{1}{|c|}{ PORTE } & \multicolumn{4}{|c|}{ GRUPOS } & TOTAL \\
\hline$\left(\mathrm{p} / \mathrm{n}^{\circ}\right.$ empregados $)$ & 1 & 2 & 3 & 4 & \\
\hline Pequena & 27 & 30 & 18 & 14 & 89 \\
\hline Média & 7 & 15 & 8 & 14 & 44 \\
\hline Grande & 4 & 3 & 1 & 3 & 11 \\
\hline Total & 38 & 48 & 27 & 31 & 144 \\
\hline
\end{tabular}


tica de preços baixos com alta capacidade de inovação e tecnologias avançadas de produção.

O grupo 2 é o que mais produz calçados. Em seguida aparece o grupo 4 , com cerca de $32 \%$ das empresas produzindo mais de mil unidades por dia, seguido pelo grupo 1 , com $16 \%$, e pelo grupo 3 , em torno de $15 \%$.

Em termos de faturamento médio mensal, o grupo 4 está muito à frente dos demais, como se verifica na Tabela 4; a maioria das empresas que o compõem se situa na faixa de faturamento acima de $\mathrm{R} \$ 400$ mil. Uma estimativa efetuada com base no valor médio das faixas de faturamento utilizadas demonstra que, enquanto o valor médio das vendas mensais das empresas dos grupos 1,2 e 3 se situa próximo aos $\mathrm{R} \$ 550 \mathrm{mil}$, no grupo 4 ele se aproxima de R\$ 1 milhão. O faturamento mais elevado das empresas do grupo 4 reflete não apenas maior produção, sendo o segundo grupo nesse quesito, mas, principalmente, o fato de produzir calçados com maior valor agregado, a preços de venda mais elevados que os demais.
Por outro lado, a busca desse posicionamento acarreta maior dificuldade de colocação de produtos no mercado, fato claramente demonstrado pela elevada ociosidade das empresas que compõem o grupo 4. Essas empresas são as que se posicionam com os preços mais elevados dentro da indústria calçadista, mas possuem, em contrapartida, os maiores custos de produção e, conseqüentemente, as menores margens de lucro. A conseqüência dessa estratégia é que $48 \%$ dessas empresas apresentam capacidade ociosa acima de $20 \%$, como se verifica na Tabela 5.

O grupo 1, composto por empresas que praticam preços baixos, mas que também declararam possuir elevados custos de produção, apresenta a mesma proporção de empresas com ociosidade acima de $20 \%$ que o grupo 4 . A explicação para isso talvez passe pela baixa de margem lucro gerada pela combinação de preços baixos e custos elevados, que pode inibir investimentos na capacidade produtiva. As empresas do grupo 3, que praticam preços elevados e possuem baixo custo operacional, são as que

\section{Tabela 3 - Produção de pares ao dia em cada grupo}

\begin{tabular}{|c|c|c|c|c|c|c|c|}
\hline \multirow[t]{2}{*}{ GRUPOS } & \multicolumn{6}{|c|}{ PRODUÇÃO (PARES/DIA) } & \multirow[t]{2}{*}{ TOTAL } \\
\hline & até 100 & $>101$ a 500 & > 501 a 1000 & > 1001 a 2000 & $>2001$ a 5000 & acima de 5000 & \\
\hline 1 & 4 & 17 & 10 & 2 & 3 & 1 & 37 \\
\hline 2 & 5 & 19 & 8 & 11 & 6 & 0 & 49 \\
\hline 3 & 2 & 14 & 7 & 3 & 0 & 1 & 27 \\
\hline 4 & 0 & 11 & 10 & 5 & 3 & 2 & 31 \\
\hline Total & 11 & 61 & 35 & 21 & 12 & 4 & 144 \\
\hline
\end{tabular}

Tabela 4 - Faturamento mensal médio em cada grupo

\begin{tabular}{|l|c|c|c|c|c|}
\hline \multicolumn{1}{|c|}{ FATURAMENTO MÉDIO MENSAL } & \multicolumn{3}{|c|}{ GRUPOS } & TOTAL \\
\hline & 1 & 2 & 3 & 4 \\
\hline Até $\mathrm{R} \$ 20.000,00$ & 2 & 2 & & & 4 \\
\hline de $\mathrm{R} \$ 20.001,00$ a $\mathrm{R} \$ 37.000,00$ & 1 & 1 & 1 & & 3 \\
\hline de $\mathrm{R} \$ 37.001,00$ a $\mathrm{R} \$ 100.000,00$ & 6 & 8 & 4 & 2 & 20 \\
\hline de $\mathrm{R} \$ 100.001,00$ a $\mathrm{R} \$ 180.000,00$ & 10 & 8 & 5 & 2 & 25 \\
\hline de $\mathrm{R} \$ 180.001,00$ a $\mathrm{R} \$ 400.000,00$ & 7 & 10 & 6 & 9 & 32 \\
\hline de $\mathrm{R} \$ 400.001,00$ a $\mathrm{R} \$ 1.000 .000,00$ & 7 & 11 & 7 & 10 & 35 \\
\hline de $\mathrm{R} \$ 1.000 .001,00$ a $\mathrm{R} \$ 2.000 .000,00$ & & 4 & 3 & 4 & 11 \\
\hline de $\mathrm{R} \$ 2.000 .001,00$ a $\mathrm{R} \$ 4.000 .000,00$ & 4 & 3 & & & 7 \\
\hline Acima de $\mathrm{R} \$ 4.000 .000,00$ & 1 & 1 & 1 & 4 & 7 \\
\hline Total & 38 & 48 & 27 & 31 & 144 \\
\hline
\end{tabular}


apresentam menor índice de ociosidade, seguidas pelas do grupo 2, que seguem uma estratégia de preços baixos e custo reduzido.

A explicação para as diferenças no posicionamento estratégico buscado pelas empresas pode ser encontrada no tipo de material utilizado de forma preponderante nos calçados fabricados. Embora o material mais utilizado pela indústria calçadista de Franca seja, amplamente, o couro bovino, as empresas com menor índice de ociosidade, decorrentes, aparentemente, de custos de produção reduzidos e de maiores margens de lucro, são as que mais fabricam calçados com materiais alternativos ao couro (material sintético e lona), conforme se verifica na Tabela 6. Esses materiais, por serem menos nobres do que o couro, apresentam custos menores, possibilitam maior produtividade e são utilizados em calçados com maior facilidade de colocação no mercado, tais como os tênis, por exemplo.

Em relação ao público-alvo, a indústria calçadista de Franca, historicamente, constituiu um pólo produtivo com foco na fabricação de calçados masculinos de couro (SINDIFRANCA, 2002). Embora tenha crescido nos últimos anos, a produção de calçados femininos e infantis ainda não é expressiva no arranjo produtivo local (SINDIFRANCA, 2002). Os calçados destinados ao público feminino, segundo os dados da amostra, se situam em um patamar inferior a $20 \%$, enquanto os fabricados para crianças não atingem 3\% da produção de calçados das empresas da região.

O Gráfico 2 mostra que as empresas do grupo 4 são as que mais diversificaram a sua produção entre calçados masculinos e femininos, com estes últimos participando com cerca de $34 \%$ dos produtos fabricados pelo grupo. Essa constatação pode explicar, parcialmente, os altos custos de produção assinalados. Para concorrer no mercado feminino, marcado por sazonalidade e tendências da moda, as empresas precisam investir em pesquisa e desenvolvimento (P\&D) e design, o que implica altos gastos com formas, modelos e sistemas de fabricação, justificando assim os elevados custos de produção registrados. A contrapartida é que os calçados femininos são também mais caros que os masculinos, principalmente quando voltados para as classes média e alta, público-alvo preferencial das empresas do grupo 4.

O grupo 3 vem em seguida, porém com participação percentual bastante inferior de calçados femininos, e pequena participação de calçados infantis, outro fato que explica os preços mais elevados, uma vez que os calçados infantis apresentam custos mais baixos de produção (ASSINTECAL, 2001).

O grupo 2, embora demonstre percentual um pouco mais elevado do que o grupo 3 na produção de calçados masculinos, é o que mais produz calçados infantis, explicando os menores preços praticados em função de custos

Tabela 5 - Capacidade ociosa média em cada grupo

\begin{tabular}{|c|c|c|c|c|c|c|c|}
\hline \multirow[t]{2}{*}{ GRUPOS } & \multicolumn{6}{|c|}{ CAPACIDADE OCIOSA (MÉDIA) } & \multirow[t]{2}{*}{ TOTAL } \\
\hline & até $10 \%$ & $>11 \%$ a $20 \%$ & $>21 \%$ a $30 \%$ & $>31 \%$ a $40 \%$ & $>41 \%$ a $50 \%$ & acima de 50 & \\
\hline 1 & 12 & 7 & 6 & 6 & 5 & 1 & 37 \\
\hline 2 & 19 & 16 & 6 & 5 & 2 & 1 & 49 \\
\hline 3 & 10 & 10 & 1 & 3 & 2 & 1 & 27 \\
\hline 4 & 11 & 5 & 8 & 4 & 2 & 1 & 31 \\
\hline Total & 52 & 38 & 21 & 18 & 11 & 4 & 144 \\
\hline
\end{tabular}

Tabela 6 - Percentual do faturamento pelo material empregado

\begin{tabular}{|l|c|c|c|c|}
\hline \multicolumn{1}{|c|}{ TIPO DE PRODUTO } & GRUP0 & GRUPO 2 & GRUPO 3 \\
\hline Calçados em Couro & $93,6 \%$ & $81,6 \%$ & $91,5 \%$ & $94,8 \%$ \\
\hline Calçados em Sintético & $4,8 \%$ & $14,5 \%$ & $7,4 \%$ & $3,5 \%$ \\
\hline Calçados em Lona & $1,7 \%$ & $3,9 \%$ & $1,1 \%$ & $1,8 \%$ \\
\hline Total & $100,0 \%$ & $100,0 \%$ & $100,0 \%$ & $100,0 \%$ \\
\hline
\end{tabular}


de produção reduzidos. O grupo 1 é o que mais produz, proporcionalmente, calçados masculinos, e conta com pequena participação de calçados infantis (menos de 3\%).

Ainda em relação ao público-alvo, as empresas que compõem os quatro grupos têm como foco principal a produção de calçados para a classe média, que representa, em média, cerca de $70 \%$ do faturamento da indústria calçadista da região, conforme se verifica na Tabela 7 .

O Grupo 4 direciona cerca de 29\% da sua produção para a classe de alta renda, enquanto os grupos 1 e 3 direcionam $16 \%$ e o grupo 2 , em torno de $14 \%$. Em contrapartida, a participação de produtos para as pessoas de baixa renda é maior no grupo 2 (17\%) do que nos outros grupos.

\section{CONSIDERAÇÕES FINAIS}

O presente trabalho teve por objetivo analisar a composição de grupos dentro da indústria de calçados da região de Franca, no estado de São Paulo, com base no posicionamento estratégico buscado por suas empresas. Foi realizada uma análise de conglomerados, que permitiu agrupar empresas amostradas em quatro grupos, com base nas avaliações de seus dirigentes sobre as vantagens competitivas de seus produtos em relação aos concorrentes locais sobre cinco variáveis estratégicas: os preços praticados; custos de produção; qualidade de produtos; tecnologia de produção; e capacidade de inovação.

O primeiro desses grupos (grupo 1) é composto, em grande parte, por empresas de pequeno porte que apresentam como características preços baixos; custos de produção reduzidos; qualidade inferior; tecnologia pouco avançada; e menor capacidade de inovação. Conclui-se que as empresas do grupo 1 perseguem uma estratégia de foco, direcionando sua produção para um segmento específico de mercado; o de calçados masculinos voltados a um público de renda baixa e média.

O grupo 2 apresenta predominância de empresas de pequeno porte, porém com participação notável de empresas de porte médio, que buscam posicionamento estratégico no mercado caracterizado por: preços baixos; custos reduzidos de produção; boa qualidade dos produtos; tecnologia de produção mais avançada do que a do grupo 1; e capacidade de inovação. É o grupo cujas empresas mais utilizam material sintético na fabricação de seus calçados. Em termos de público-alvo, é o terceiro

Gráfico 2 - Percentual da produção por tipo de produto: calçados masculinos, femininos e infantis

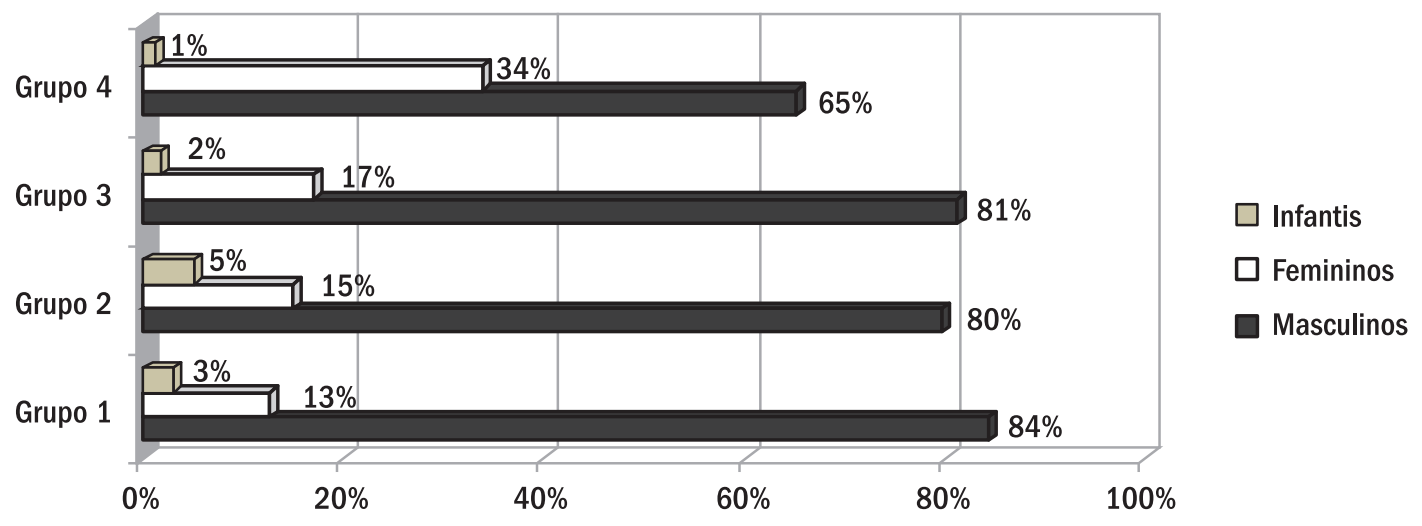

Tabela 7 - Percentual do faturamento por classe de renda

\begin{tabular}{|l|c|c|c|c|}
\hline \multicolumn{1}{|c|}{ CLASSE DE RENDA } & GRUP0 1 & GRUP0 2 & GRUP0 3 & GRUP0 4 \\
\hline Baixa & $15,0 \%$ & $17,4 \%$ & $11,5 \%$ & $3,7 \%$ \\
\hline Média & $69,0 \%$ & $68,4 \%$ & $72,7 \%$ & $66,8 \%$ \\
\hline Alta & $16,0 \%$ & $14,2 \%$ & $15,8 \%$ & $29,5 \%$ \\
\hline Total & $100,0 \%$ & $100,0 \%$ & $100,0 \%$ & $100,0 \%$ \\
\hline
\end{tabular}


grupo na fabricação de calçados femininos, e o primeiro na de calçados infantis. As empresas do grupo 2 buscam a estratégia de baixo custo.

O grupo 3 é composto, predominantemente, por empresas de pequeno e médio porte. O posicionamento estratégico das indústrias deste grupo é refletido nas seguintes características: preços elevados (menores apenas que os do grupo 4); os custos de produção mais reduzidos entre todos os grupos; padrão médio de qualidade; tecnologia com tendência avançada; e baixa capacidade de inovação, entretanto. Aparentemente, o posicionamento estratégico buscado por este grupo é o que apresenta os melhores resultados em termos de colocação dos seus produtos, uma vez que é o que se situa no menor patamar de capacidade ociosa entre os grupos analisados. Assim como para as empresas do grupo 2, assume-se que as do grupo 3 também buscam a estratégia de menor custo.

Finalmente, o grupo 4 é composto principalmente por empresas médias e grandes, que adotam posicionamento estratégico caracterizado por: preços altos; elevados custos de produção; tecnologia mais avançada; alta qualidade; e grande capacidade de inovação. Este grupo é o que mais diversificou sua produção, com os calçados destinados ao público feminino representando mais de um terço dos produtos fabricados. Verificou-se que as empresas do grupo 4 buscam a estratégia de diferenciação no mercado.

A partir dos resultados alcançados, conclui-se que as empresas que fazem parte do grupo 1 estão em posição estratégica desfavorável em comparação aos outros grupos identificados na pesquisa, por fabricar produtos pouco diferenciados e com preços relativamente superiores. Às empresas deste grupo, recomenda-se a decisão de adotarem as medidas necessárias para alcançarem a liderança ou, ao menos, a paridade de custos em relação às demais, o que exige investimentos na modernização de instalações; alternativamente, podem buscar alguma diferenciação. A escolha estratégica deve se basear necessariamente nas capacidades, nos recursos e nas limitações de cada empresa.

Como limitação desta pesquisa, destaca-se o fato de a população investigada ter sido definida de forma estreita, contando apenas com empresas calçadistas da região de Franca, e tendo sido excluídas as microempresas. Assim, não há possibilidade de generalização dos resultados para empresas calçadistas de outras regiões brasileiras, devido à particularidade do universo de pesquisa, e também ao método de pesquisa utilizado, que é um método descritivo.

Uma sugestão para estudos futuros seria a realização de pesquisas semelhantes em outras regiões produtoras de calçados no Brasil, em especial com empresas do vale dos Sinos (RS), devido à sua importância na produção e comercialização de calçados brasileiros. Dessa forma, poderiam ser feitas comparações entre os resultados alcançados em diferentes regiões, possibilitando ao setor a elaboração de planos de ação para atacar suas fraquezas e desenvolver competitividade.

\section{REFERÊNCIAS}

ASSOCIAÇÃO BRASILEIRA DAS INDÚSTRIAS PRODUTORAS DE CALÇADOS. Resenha Estatística da Indústria Calçadista 2006. Disponível em: <http://www.abicalcados.com.br>. Acesso em: abr. 2006.

ASSOCIAÇÃO COMERCIAL, INDUSTRIAL E DE SERVIÇOS DE NOVO HAMBURGO. Resenha Estatística Sobre Calçados. Novo Hamburgo/RS, 1999

ANDERSON, C. H.; VINCZE, J. W. Strategic Marketing Management. Boston: Houghton Mifflin Company, 2000.

ASSINTECAL. Quantificação da Produção da Indústria Calçadista. Novo Hamburgo, RS: Assintecal, abril de 2001.

CARVALHO NETO, S. Competência para exportar: alternativa de crescimento para a indústria de calçados de Franca. 2004. Dissertação (Mestrado) Centro Universitário de Franca, São Paulo, 2004.

CRAVENS, D. W. Strategic Marketing. 4. ed. Chicago: Irwin, 1994.

DAY, G. S. Estratégia voltada para o mercado: processos para a criação de valor dirigidos ao cliente. Rio de Janeiro: Record, 1990.

DAY, G. S.; WENSLEY, R. Assessing advantage: a framework for diagnosing competitive superiority. Journal of Marketing, v. 52, p. 1-20, Apr. 1998.

DIMINGO, E. The fine art of positioning. The Journal of Business Strategy, Mar./Apr. 1988.

DOURADO, C. A. Marketing na micro e pequena empresa fabricante de calçado masculino: o caso de Franca. 2001. 106 f. Dissertação (Mestrado em Administração) - Centro Universitário de Franca, São Paulo, 2001.

FIGUEIREDO, K. F; ALMEIDA, L. F. F. As barreiras à exportação de calçados brasileiros. In: ROCHA, A. (Org.). Gerência de exportação no Brasil. Rio de Janeiro: UFRJ, 1988.

HAIR, J. F; ANDERSON, R. E.; TATHAM, R. L.; BLACK, W. C. Multivariate Data Analysis. Englewood Cliffs: Prentice Hall, 1998.

HENRIQUES, L. F. R. A análise da competitividade da indústria calçadista do vale dos Sinos: uma aplicação da metodologia de Michel Porter. 1999. 148 f. Dissertação (Mestrado) - Universidade Estadual de Campinas, Instituto de Economia, Campinas, 1999. 
HOOLEY, G. J., SAUNDERS, J. A., PIERCY, N. F. Estratégia de marketing e posicionamento competitivo. 2. ed. São Paulo: Prentice Hall, 2001.

KAPFERER, J. N. As marcas: capital da empresa. Porto Alegre: Bookman, 1998.

KOHLI, C. S.; LEUTHESSER, L. Product positioning: a comparison of perceptual mapping techniques. The Journal of Product and Brand Management, Santa Barbara, v. 2, n. 4, p. 10-18, 1993.

KOTLER, P.; ARMSTRONG G. Princípios de marketing. São Paulo: Prentice Hall, 1991.

LAMBIN, J-J. Marketing estratégico. Alfagride: McGraw-Hill, 2000.

MACHADO NETO, A. J. O novo cadastro da indústria calçadista francana. Trabalho apresentado em palestra no Sindicato da Indústria de Calçados de Franca, Franca, 2004.

MALHOTRA, N. K. Pesquisa de marketing: uma orientação aplicada. 3. ed. Porto Alegre, Bookman, 2001, 719 p.

MATTAR, F. N. Pesquisa de marketing. São Paulo: Atlas, 1996.

PICCININI, V. L'Industrie de la chaussure Brésilienne face aux mutations internationale: stratégies et politique du personnel des enterprise de la region de "Vale dos Sinos". 1990. Thése (Doctorat d'Economie du Travail et de la Production) - École Supérieure des Affaires, Université PierreMendès-France, Grenoble, 1990.

MACHADO NETO, A. J. Os determinantes do comportamento exportador da indústria calçadista francana. 2006. Tese (Doutorado) Faculdade de Economia, Administração e Contabilidade da Universidade de São Paulo, 2006.

PORTER, M. E. Estratégia competitiva: técnicas para análise de indústrias e da concorrência. Rio de Janeiro: Campus, 1986.
PROCHNIK, V.; UNE, M. Y. A migração da cadeia produtiva de calçados para a região Nordeste do Brasil. Rio de Janeiro: Instituto de Economia/ UFRJ, 2002. Disponível em: <http://www.desenvolvimento.gov.br/arquivo/ sti/publicacoes/futAmaDilOportunidades/futIndustria_2_10.pdf>. Acesso em: 14 maio 2007.

REIS, C. N. A indústria brasileira de calçados: inserção internacional e dinâmica interna nos anos 80. 1994. 257 f. Tese (Doutorado) Universidade Estadual de Campinas, Instituto de Economia, 1994.

RIES, A.; TROUT, J. Posicionamento: a batalha por sua mente. São Paulo: Pioneira, 1999.

SAMPAIO, M. H. A.. Crise afeta o setor calçadista no ano de 2005. Indicadores Econômicos FEE, Porto Alegre, v. 34, n. 1, p. 23-30, jul. 2006 .

SERVIÇO BRASILEIRO DE APOIO ÀS MICRO E PEQUENAS EMPRESAS Projeto APL Franca. Franca, SP, 2004.

SINDICATO DA INDÚSTRIA DE CALÇADOS DE FRANCA. A cadeia coureiro-calçadista. Franca, SP: Natrontec, 2002.

SLACK, N. Vantagem competitiva em manufatura: atingindo competitividade nas operações industriais. São Paulo: Atlas, 1993.

SMITH, M. S. J. A administração contábil nas micro e empresas de pequeno porte do setor calçadista de Franca. 2000. Dissertação (Mestrado) Centro Universitário de Franca, Franca, 2000.

ZHANG, Y. Country-of-origin effect: the moderating function of individual difference in information processing. International Marketing Review, London, v. 14, n. 4, p. 266-287, 1997.

Artigo recebido em 11.07.2006. Aprovado em 29.10.2007.

\section{Alfredo José Machado Neto}

Professor e Pró-Reitor de Administração do Centro Universitário de Franca.

Doutor em Administração de Empresas pela Faculdade de Economia, Administração e Contabilidade, Universidade de São Paulo.

Interesses de pesquisa nas áreas de internacionalização de empresas, cenários econômicos e desenvolvimento regional.

E-mail: alfredo@facef.br

Endereço: Rua Jonas Deocleciano Ribeiro, 919, São José, Franca - SP, 14400-230.

\section{Janaina de Moura Engracia Giraldi}

Professora da Faculdade de Economia, Administração e Contabilidade de Ribeirão Preto, Universidade de São Paulo.

Doutora em Administração de Empresas pela Faculdade de Economia, Administração e Contabilidade, Universidade de São Paulo.

Interesses de pesquisa nas áreas de marketing e estratégias empresariais.

E-mail: jgiraldi@usp.br

Endereço: Rua Clemente Ferreira, 955, Jd. São Luís, Ribeirão Preto - SP, 14020-410. 